\title{
Traumatic influence of the attitude towards one's own gender as a factor in the development of eating disorders
}

\author{
Aleksandr Tsapenko ${ }^{1,2, *}$ \\ ${ }^{1}$ Don State Technical University, Gagarin Square. 1, 344000 Rostov-on-Don, Russia \\ ${ }^{2}$ Psychological Safety Center, Zhuravleva st., 344000 Rostov-on-Don, Russia
}

\begin{abstract}
At present, the amount of people suffering from various types of eating disorders is steadily increasing all over the world. A large proportion is occupied by people with manifestations of anorexia. Primarily this disorder affects female representatives at the age of 13-20 years. Taking into account the severity of the consequences that anorexia leads to, cases of death are increasingly being recorded, including adolescents. That's why the question of providing effective assistance to such patients is especially relevant. However, without establishing the true causes, the results achieved during the treatment may be only short-term. In this connection, the author made an attempt to look at the problem more deeply. Thus, the article is devoted to the consideration of the causes of anorexia of adolescent girls, lying in the field of the unconscious, in particular, in a deep psychological trauma received in childhood. According to the author, the reasons of this trauma are the perception as a humiliation of the manifestations of the brother's admiration or friends' son from the girl's parents, as opposed to the lack of attention, warmth and care towards her. The arising misunderstanding of the reason for such a different attitude contributes to the formation of a girl's confidence that it is better to be a boy and, as a result, an unwillingness to be a woman. This, in turn, leads to anorexic behavior, as anorexia can inhibit the transformation of the body into a woman. The given assessment was confirmed in a conducted study among 128 girls aged 13-18 years with various eating disorders, including 46 with manifestations of anorexia nervosa. The substantiation of the hypothesis put forward at the beginning of the study was checked by means of a statistical method - the Fisher- $\varphi$ test.
\end{abstract}

\section{Introduction}

Against the background of the growing number of people suffering from various eating disorders (ED), the issues of anorexia are being paid more attention to during recent decades [1]. Concerned with the problem of spread and rejuvenation of this disorder, scientists and practitioners make numerous attempts to find the causes of its appearance $[2,3,4,5,6]$.

\footnotetext{
*Corresponding author: sirius-gipno@mail.ru
} 
At the same time, despite a significant amount of the researches in this field, among the psychological causes of anorexia not enough attention, in our opinion, is paid to the unconscious mechanisms. We, taking as a bases the views of Z. Freud, E. Berne, S. Ferenczi, believe that one of the reasons for the behavior leading to anorexia may be a deep psychological trauma received in childhood $[7,8,9]$.

So, approximately by the age of 3 , there comes a phase when a child reveals the need for narcissism, admiration for his/her actions and exhibitionism [10]. If during this period parents and inner circle do not support such manifestations, that is, they do not praise or admire these signs and, on the contrary, humiliate and make fun of them, then occurs the interjection [9] of these humiliations and the consequences of the received trauma can be quite severe. In the subsequent stages of the child's development, the already fixed psychological trauma can be reinforced at the expense of resentment arising because of the comparison with the sibling in favor of the latter, more lenient and attentive attitude towards him.

These emotionally acute experiences of the child, which he cannot cope with due to the age-related immaturity of the psyche and/or the intensity of the impact, as a rule lead to neurosis. Starting from adolescence, the neurosis formed in this case, in relation to ED, can be detected in the form of anorexia. And then we will deal with anorexia nervosa (AN).

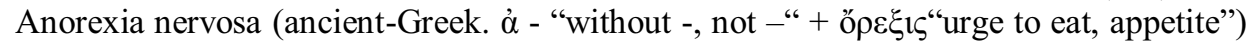
is a disorder characterized by the deliberate weight loss caused and maintained by the patient, also by means of the diet, excessive physical activity, taking emetics, laxatives and diuretics, as well as drugs that reduce appetite [11].

The given disorder is associated with a specific psychopathological fear of obesity, which becomes an annoying idea, and patients establish for themselves a low limit of their bodyweight. So, the main sign of anorexia nervosa is a critical weight loss and body exhaustion.

Among the secondary complications the following ones are singled out: metabolic disorders, endocrine diseases, changes in blood composition, dry skin of the body, decreased blood pressure, disorders of the gastrointestinal tract. Along with this, sexual development disorders, growth disturbance and amenorrhea are the obligatory diagnostic signs for AN [11].

It is worth noting that mostly female representatives are subject to anorexia, and only 5\% of this disorder is detected in boys, adolescents and men [12]. As a rule, it is more common in adolescent girls and young women [11]. The highest incidence rates of anorexia nervosa are peculiar for the age of 13-20 years, less often the onset of AN occurs in the prepubertal period and mature age [13].

Within the framework of our research, these facts are given a significant place as the circumstances in which the problem escalates.

Speaking about the psychological causes of the considering disorder, the opinion of L. Hay arouses interest. She believes that anorexia is an exaggerated fear, self-hatred and denial of oneself as a person. For girls, it is unwillingness to accept her nature and femininity [14].

This is comparable to our views. So, we believe that exhaustion, as a result of anorexia, may be a manifestation of a girl's rejection of femininity. That is, due to the received childhood trauma, the girl does not want to be a woman, and therefore with the help of anorexia eliminates secondary sexual characteristics: slowdown or complete stop of breast growth, lack of pelvic development and amenorrhea occur, etc. In other words, she tries not to grow up, but to remain a teenager, as if a boy, turning herself with the help of anorexia into a teenage boy. It happens due to the girl's belief that it's better to be a boy, more profitable, because boys are more loved and they are forgiven a lot. Such confidence arises in connection with the attitude of parents towards the brother observed in childhood - he is praised more for less, he is allowed more, he is proud of more as opposed to the girl. For example, when a brother gets a "C," he is praised for "not getting " $F$ ", while there is no 
attention paid to the excellent girl's grades, and when a girl gets good or satisfactory mark, she is scolded or even punished, or her educational and creative achievements remain unnoticed. In this connection, the girl has a misunderstanding of the reason for this difference in the attitude of parents, and as a result, she tries to eliminate this difference by "becoming" a boy. Anorexia can slow down the transformation of the body into a woman, so there is a refusal to eat.

Thus, as the main hypothesis of the given study, we highlight the following - the cause of anorexia in girls may be a child psychological trauma received on the basis of gender.

Based on the hypothesis, the objectives of the study are:

1. To identify the presence/absence of a child psychological trauma in girls aged 13-18 years with signs of anorexia nervosa and in girls with other eating disorders, using the survey method.

2. To conduct a comparative analysis of the survey results on the identification of child psychological trauma among the girls aged 13-18 years who have signs of AN and girls with other ED.

3. To determine factors that can influence the occurrence of child psychological trauma in girls on the basis of gender.

\section{Research methodology}

The sample consisted of 128 girls with ED aged 13-18 years, including 46 people with signs of AN, including those with an established diagnosis, and 82 people with other ED (obesity (47 people), bulimia (26 people), hyperphagia ( 21 people)). The study was conducted on the basis of the Psychological Safety Center, and also by means of the Internet (including video link). Taking into account the age of the participants and the sensitivity of the subject of the study, special attention was paid to the creation of a psychologically safe and comfortable environment provided by the support of a psychotherapist. Participation in the study of girls under the age of 16 was allowed with the prior consent of their parents, but without their personal presence.

The following methods were used:

1. As the main method, the author's childhood injuries identification questionary was used in combination with a structured psychoanalytic interview.

2. Statistical methods of data processing: The Fisher $-\varphi$ criterion.

The childhood injuries identification questionnaire consists of 14 main closed-type questions and one open-ended question for receiving general information. The questions are structured according to categories, reflecting the participants' feelings of love from their parents, admiration from them, and humiliation, both from them and from siblings and peers.

Each answer is evaluated on a 10-point scale. In questions from 1 to 5, the points are counted in direct order from " 0 ". In questions 6 to 8 and 10 to 15 , the scores are counted in the opposite direction, i.e., if the respondent answered " 0 " - it is estimated as " 10 ", and vice versa. In addition to the score estimation, each question provides the possibility of a comment, where the participants could reflect any situation, their emotions or other explanations that are important in their opinion.

The number of points is calculated both for each respondent and for each question. The average value is derived from the total score on the question scale. Also, the absolute quantitative indicators are transferred into percentage expressions in grouping scales.

The collected amounts are conventionally divided into 3 levels. Within one scale, a high level of traumatization corresponds to the number of points from 0 to 3 , an average from 4 to 7 , low from 8 to 10 points. The maximum value on each scale is equal to 10 points, and on the questionnaire -140 points.

In general, according to the questionnaire for each participant: 
A high level of traumatization (0-42 points) indicates a sense of humiliation, her own uselessness, lack of love, warmth and care from the parents' side. This can be regarded as a reflection of the child's psychological trauma.

The average level (43-98 points) indicates that the respondent feels insufficient manifestation of love, care and warmth from the parents' side, as well as possible conflicts and the lack of close and trusting relationships with siblings.

The low level (99-140 points) reflects the psychological well-being of the respondent, the presence of close and warm relations in the family during childhood, which indicates the absence of child psychological trauma.

The interview was aimed at clarifying the questions of the questionnaire, assistance in formulating answers, and the girls were also instructed to describe their relationships with their parents, siblings and other close relatives in childhood, how successful they were, according to their close environment, and their own perception, starting from preschool age, how they related to their appearance, whether there was a change in this attitude compared to their childhood, etc. Special attention was paid to the evaluation of the comparison of the mother's attitude to the girl's brother, as well as the comparison with other boys and girls.

In 33 cases, the survey was conducted entirely in the interview format because of the fact that the expanded version of the test caused some embarrassment of the participants, and as a result, made it difficult to complete it.

To substantiate the results of the study, statistical processing of the obtained data was carried out, which consisted in assessing the differences in the level of manifestation of childhood trauma in girls with signs of anorexia and in girls with other ED. The statistical hypothesis $\mathrm{H}_{0}$ suggests an equal level of gender-based trauma in these girls, while the alternative hypothesis $\mathrm{H}_{1}$ suggests differences in the manifestation of this trauma in girls with AN compared with the girls with other ED. Software and hardware used in the study: Google services -"Forms" and "Tables" for conducting the survey, Microsoft Excel 2007 for statistical data processing.

\section{Results}

The survey of the participants of the study revealed the nature of girls' perception of expressions of love and admiration from their parents in childhood, as well as humiliation, including from siblings and peers. Based on the data obtained, it was identified that all respondents had manifestations of child psychological trauma (see Fig. 1).

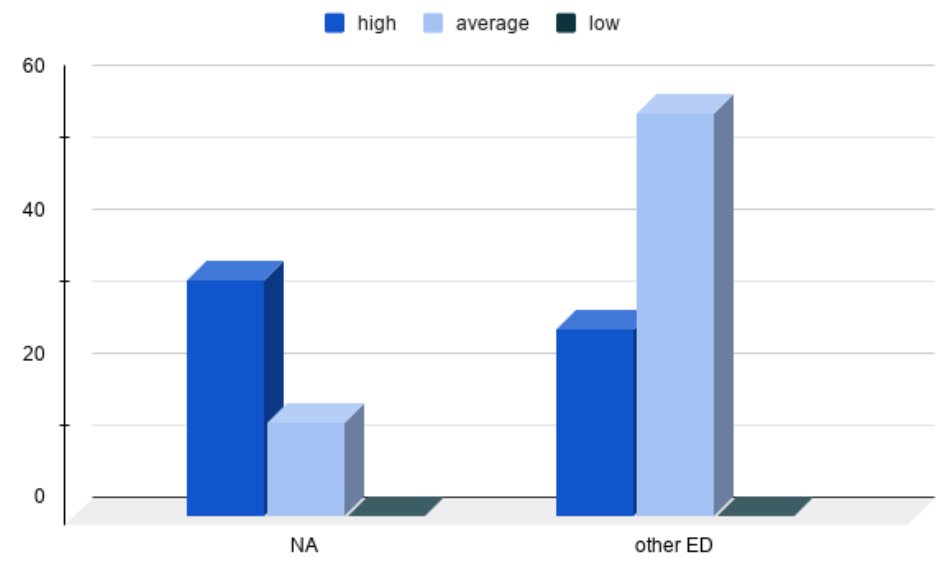

Fig. 1. The level of reflection of childhood trauma in girls with ED and AN (in terms of admiration/humiliation). 
This shows that none of the participants had a low level of injuries. Thus, $72 \%$ of girls with signs of AN revealed a high level of reflection of psychological trauma received in childhood. Among young girls with other ED, the average level previals-68\%. At the same time, it should be noted that the average values on the scales in both cases are approximately in the same echelon, the differences are only questions related to the parents' admiration for outsider boys and the respondents' desire to be a boy (see Table 1.), which can be regarded as a manifestation of a gender-based trauma.

Table 1. Average values of the results of the girls' responses with AN and with other ED.

\begin{tabular}{|c|c|c|c|}
\hline \multirow[b]{2}{*}{ № } & \multirow[b]{2}{*}{ Question } & \multicolumn{2}{|c|}{ Average value } \\
\hline & & $\begin{array}{l}\text { Girls with } \\
\text { AN }\end{array}$ & $\begin{array}{l}\text { Girls with } \\
\text { other ED }\end{array}$ \\
\hline 1 & $\begin{array}{l}\text { How much did you feel the love of your parents in } \\
\text { childhood? }\end{array}$ & 2.2 & 2.4 \\
\hline 2 & $\begin{array}{l}\text { Did your parents admire you when you were little? For } \\
\text { example. said that you were the most beautiful. the } \\
\text { smartest. the best }\end{array}$ & 1.5 & 2.1 \\
\hline 3 & $\begin{array}{l}\text { Did your parents brag about you to other people? (your } \\
\text { beauty. achievements. successes. etc.) }\end{array}$ & 1 & 1.7 \\
\hline 4 & How often were you praised in the childhood? & 1.4 & 2.1 \\
\hline 5 & $\begin{array}{l}\text { Do you think that you were little praised for your merits. } \\
\text { which were important to you in childhood? }\end{array}$ & 0.9 & 1.7 \\
\hline 6 & $\begin{array}{l}\text { Did your parent ever humiliate you? For example. they } \\
\text { insulted you. laughed at you. at how you look. what you } \\
\text { do }\end{array}$ & 5.3 & 5.2 \\
\hline 7 & $\begin{array}{l}\text { Did your parents laugh at you in the presence of other } \\
\text { children or adults? Or did they say in the presence of } \\
\text { others that you were not capable of anything. that you } \\
\text { were not beautiful. that your achievements were } \\
\text { nonsense. etc. }\end{array}$ & 5.4 & 4.9 \\
\hline 8 & $\begin{array}{l}\text { Did your classmates or friends laughed at you. humiliate } \\
\text { you in any way? }\end{array}$ & 4.1 & 4.3 \\
\hline 10 & $\begin{array}{l}\text { Did your brother or sister ever laugh at you. at your } \\
\text { appearance. or humiliate you in any other way? For } \\
\text { example. if you have an older brother. did he invite } \\
\text { friends while your parents were away and made } \\
\text { unnecessary jokes about you? }\end{array}$ & 0.6 & 4.2 \\
\hline 11 & $\begin{array}{l}\text { Do you think your parents love your brother or sister } \\
\text { more than they love you? }\end{array}$ & 1.4 & 2.9 \\
\hline 12 & $\begin{array}{l}\text { Was your brother or sister praised more even for some } \\
\text { small things than you were praised for the great } \\
\text { achievements? }\end{array}$ & 1.7 & 3.1 \\
\hline 13 & $\begin{array}{l}\text { Were there more indulgences and condescension for a } \\
\text { brother or sister than for you? }\end{array}$ & 1.6 & 2.9 \\
\hline 14 & $\begin{array}{l}\text { Did your parents admire any other boy more than they } \\
\text { admired you? (for example. a friends' son. a cousin. a } \\
\text { classmate) }\end{array}$ & 3.8 & 5.2 \\
\hline 15 & Would you like to be born a boy? & 1.3 & 6.3 \\
\hline & Total: & 35.8 & 48.4 \\
\hline
\end{tabular}

Also, according to the results of the carried out survey, it was found that girls prone to anorexia had acute psychological trauma in childhood, not from direct humiliation, but from the difference in the attitude of their parents to their brother, rather than to her. It was exactly this difference that the participants perceived as a humiliation, the emotional trial of which was relevant and manifested even during the interview. Alongside with this, some girls 
experienced trauma not because of the comparisons with brother (due to his absence), but when her parents praised and admired the close friends' son or a cousin more than their daughter. At the same time, the merits and qualities of the girl herself were either hushed up or minimized, while the slight merits of the third-party boy/youngster were glorified. These feelings of vulnerability were accumulated and could eventually could lead to thoughts of not wanting to be a woman (see Fig. 2).

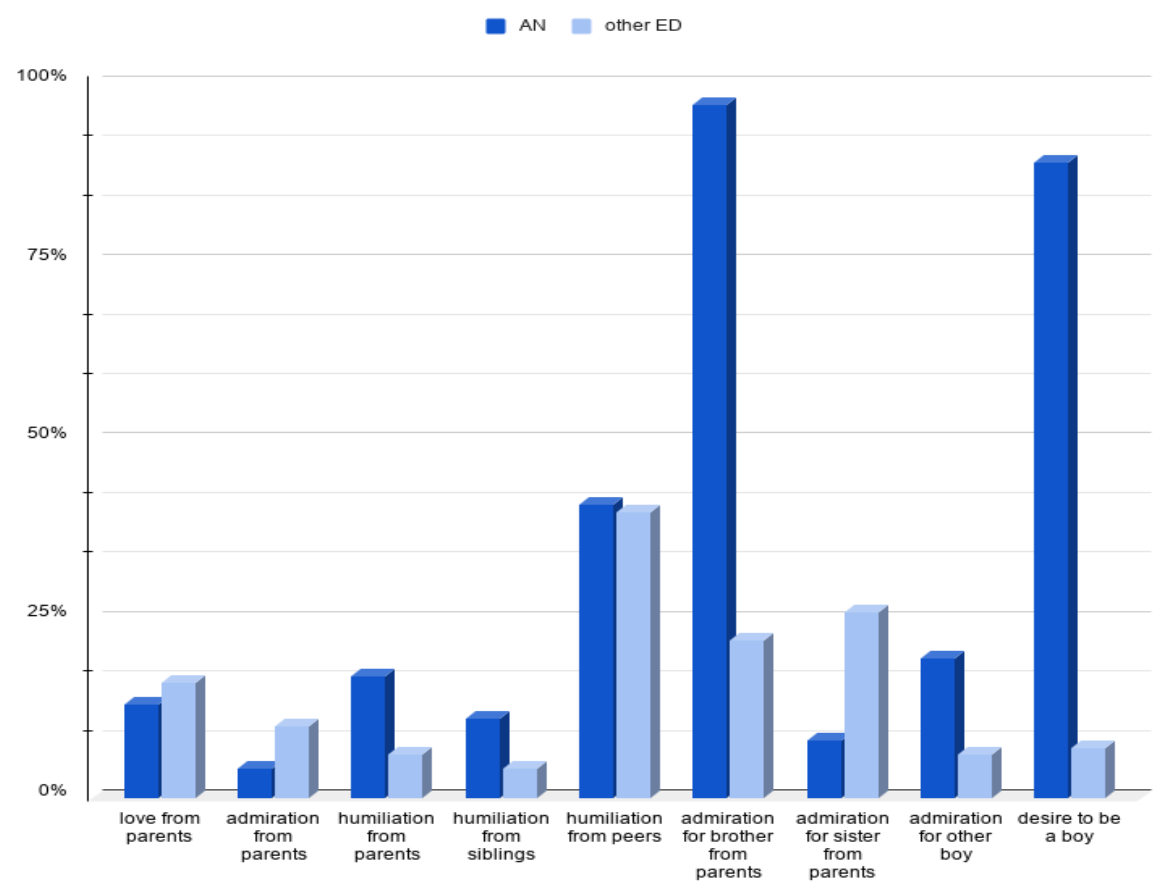

Fig. 2. The results of a survey to identify childhood trauma (in terms of humiliation, including indirect) in girls with ED and AN.

The survey revealed that only 6 girls with AN (which is 13\%) and 13 people (16\%) with other ED felt the love of their parents. At the same time, the scores on this scale are mainly at the average level and range from 5 to 8 points. None of the participants experienced the maximum confidence in love of their parents. Among the girls with AN the manifestations of love from their parents is remembered mostly either by those who do not have siblings (2 people), or have sisters ( 3 people). Among the women with other ED, the presence/absence of any of the siblings is represented approximately equally (brother -6 people, sister -4 people, no siblings -3 people).

The average value of the scale of "love from parents" was: among the participants with $\mathrm{AN}-2.2$ points, among the participants with other ED -2.4 points. Thus, all the girls have lack of love from their parents' side.

The scale "admiration from parents" is presented in a generalized form by the answers to three questions about whether the parents expressed admiration for the girl's beauty and her achievements in childhood, whether they bragged about her to others, and how often they praised her. This scale-grouping includes respondents who have the level of answers above 3 points for all three questions. At the same time, it is worth noting that both groups of participants do not have maximum assessments of the indicated issues and are equal to 4-7 points. Almost all respondents noted that they did not have enough praise from their parents' side in childhood. So, only $4 \%$ of the girls with AN and $10 \%$ with other ED experienced admiration. 
Even in the absence of love from parents, only a few participants of our study were subjected to direct humiliation from them, including humiliation in the presence of other people: among girls with AN-3 people, with other ED-5 people. However, the respondents with AN regarded more favorable attitude (in their opinion) to siblings as a humiliation, and first of all, this attitude was revealed to their brothers and girls considered that their parents loved their brothers more.

This was especially emphasized if the girl was humiliated by her brother / brothers. Cases of such humiliation were described by 14 people during the interview. Vivid examples are the stories of 4 participants with AN. So, they noted the cases from childhood when they were subjected to ridicule and bullying by their older brother and his friends due to the fact that they were girls: as a joke, they took off their underpants, looked at their genitals and laughed. At this moment, against the background of the experienced feeling of helplessness due to the difference in physical strength, the girls fixed the opinion that it is better to be a boy.

Speaking about the love of parents for sibling, girls with AN believe that their parents gave their preferences in love and admiration to their brothers (97\%). Among those who have sisters, $8 \%$ experienced less love from their parents. Among girls with other ED, these indicators were distributed as follows: $22 \%$ - have brothers, $26 \%$ - have sisters.

The given results were reflected in the scales "admiration of brother from parents" and "admiration of sister from parents", which included the respondents' answers to three questions with scores 0-3 points (see Fig. 2).

Alongside with feeling of lack of love and recognition from parents, $19 \%$ of respondents with $\mathrm{AN}$ and $6 \%$ with other ED experienced vexation in connection with the admiration for other boys by their mother or father: cousins/second cousins, friends' son, brothers' friends or girls' peers. These boys were held as an example, praised for achievements that seemed insignificant to the girls against the background of rare praise of the girls.

According to the girls' recollections, many of them were subjected to ridicule, jokes and deception by their peers, which they regarded as humiliation. This was indicated by $19 \%$ of the participants with AN and 33\% with other ED. At the same time, most of the respondents with AN remember cases of humiliation from boys, and girls with other ED note mockery and bullying from girls, and first of all, because of the apparent features of appearance (a tendency to fatness, a special shape of the ears, etc.).

Regarding the desire to be a boy, among girls with AN, this index is equal to $89 \%$ (41 people), while $66 \%$ of them have a brother, $15 \%$ - a sister, $19 \%$ - do not have any siblings. Among girls with ED, 6 people (7\%) expressed apparent willingness to be a boy, $33 \%$ of them have a brother, $17 \%$ - a sister, $50 \%$ - do not have any siblings. During the interview, the participants with AN reported that they have such a desire due to the fact that everyone loves boys more and "in general, it's cooler to be a boy", and the respondents with other ED, who had neither brother nor sister, wanted to be a boy because of the lack of love from their parents, alongside with the admiration for third-party boys.

As a substantiation of her desire, one of the participants with AN said that her belief about the greater love of others for boys than for girls was formed as a result of observing in childhood the difference in the attitude of her grandmother to her alcoholic son, to whom she showed love and care, compared with the discontent and constant scolding of her daughter (the girl's mother), who did not have bad habits and led a socially approved lifestyle. Also, 5 respondents with $\mathrm{AN}$ and 1 with other ED noted that after being humiliated by their peers (boys), they wanted to resemble them.

Following the survey and interview for checking of the proposed hypothesis, the obtained data were subjected to a statistical processing using the Fisher-ptest. For comparison, the distribution of the following quantitative signs was taken: a high level of traumatization in girls with AN - 71.7\% and a high level of traumatization in girls with other ED - 31.7\%. 
Thus, $\varphi_{1}=2.020$ at $71.7 \%, \varphi_{2}=1.196$ at $31.7 \%$. On the basis of the obtained data, the $\varphi_{\mathrm{emp}}$ value was calculated, which was $\varphi_{\mathrm{emp}}=4.47$ at the significance level $\mathrm{P} \leq 0.01$ and $\varphi_{\mathrm{cr}}=2.28$.

As the obtained $\varphi_{\text {emp }}$ value exceeds the corresponding critical value for the level of $1 \%$, this allows us to conclude that the empirical hypothesis $\mathrm{H}_{1}$ about differences is accepted at a high level of significance. That is, in girls with manifestations of anorexia, child psychological trauma on the basis of gender is more pronounced than in girls with other ED.

\section{Discussion}

The given result is corresponded with the above given theoretical positions, which are reduced to the fact that the girl's unwillingness to be a woman, due to trauma, can lead to such eating behavior. A similar opinion is shared by V. Broitigam and P. Christian, who see the ambivalent attitude of the girl to the sexual role as the basis of anorexia nervosa [15].

In the aspect of the impact of psychological trauma on the development of AN, the views of Swedish specialists are conformed [16], whose studies have shown that anorexia nervosa can be formed as a group of behavioral syndromes that manifest themselves in adolescence, but have "roots" in early childhood. According to their supposal, some cases of AN are just one of the later symptoms of a long-term empathy disorder that existed since early childhood and these data are associated with the results of our study.

European scientists have a similar point of view [17], they found that during formation of a deprivation relationship with father, girls develop dissatisfaction with their appearance, anxiety about their success in the opposite sex, which can later lead to eating disorders, including anorexia.

Alongside with this, there are many studies revealing the dependence of AN with family relationships, type of upbringing, and also genetic predisposition and physiological characteristics $[4,18,19,20,21]$. Which, in turn, confirms the multifactorial nature of the investigated problem, but does not exclude the validity of our results.

\section{Conclusions}

The proposed hypothesis found evidence. Thus, by means of the survey and interview methods, the fact of the manifestation of childhood trauma on the basis of gender in girls with AN and other ED was established, and the application of the Fisher- $\varphi$ criterion showed the reliability of the results of its manifestation to a greater extent in the respondents with signs of AN.

Among the factors that can influence the occurrence of child psychological trauma in girls on the basis of gender, it is possible to single out the following:

- feeling of humiliation from the parents' side, including mentioning of the appearance, unworthiness and lack of positive signs,

- perception of an excellent behavior in favor of brother from the parents' side,

- the feeling and real cases of humiliation on the part of the brother/brothers,

- perception of parents' admiration for third-party boys (cousin, friends' son, brother's friend),

- feelings and real cases of humiliation from peers (boys),

- feeling of lack of love and admiration from parents' part - as a background of one of the above-mentioned factors.

Thus, the data obtained by us showed that if the psychological trauma in childhood was fixed by a humiliation based on the bases of gender status and the difference in the parents' attitude in favor of a brother or another boy, then this formed a girl's unwillingness to be a 
woman, which in adolescence was manifested in the form of anorexia and anorexic tendencies.

The identification of the given dependence, as one of the causes of anorexia nervosa development, can be of value in determining the algorithm for providing psychotherapeutic assistance to girls suffering from this disorder, including the initial stage of the disease in order to prevent the most unfavorable outcomes.

\section{References}

1. K.A. Glashouwer, P.J. de Jong, Current Opinion in Psychology (2021) https://doi.org/10.1016/j.copsyc.2021.03.008

2. G. Risso, R.M. Martoni, S. Erzegovesi et al., Neuropsychologia 149, 107635 (2020) https://doi.org/10.1016/j.neuropsychologia.2020.107635.

3. M.A. Guseva, Bulletin of medical Internet conferences 5(5), 726 (2015) https://www.elibrary.ru/item.asp?id=23525434

4. E.I. Skugarevskaya, T.P. Petrovich, O.A. Skugarevsky, Psychiatry, psychotherapy and clinical psychology 2, 120-129 (2011) https://www.elibrary.ru/item.asp?id=16378015

5. N.A. Mazaeva, N.V. Samochatova, Mental disorders in general medicine 4, 20-30 (2008)

6. C. Peat, J.E. Mitchell, H.W. Hoek, S.A. Wonderlich, International Journal of Eating Disorders 42(7), 590-594 (2009) doi: 10.1002/eat.20717

7. Z. Freud, Introduction to psychoanalysis: lectures (SSU Publishing House, Moscow, 2007)

8. E. Bern, Transactional analysis in psychotherapy. Systemic individual and social psychiatry (Academic Project, Moscow, 2015)

9. S. Ferenczi, Introjection and transference (Publishing house "ERGO", Izhevsk, 2011)

10. E. Erikson, Childhood and society (Publishing house "University Book", St. Petersburg, 1996)

11. MKB 10 - International Classification of Diseases of the $10^{\text {th }}$ revision, https://mkb10.com/index.php?pid $=4288$

12. A.Sh. Tkhostov, Psychology of corporeality (Smysl, Moscow, 2002) http://pedlib.ru/Books/5/0055/5_0055-1.shtml

13. E.E. Balakireva, Psychiatry 5(16), 44-55 https://www.elibrary.ru/item.asp?id=18863879

14. L. Hey, Heal your body with love (Eksmo, Moscow, 2021)

15. V. Broitgam, P. Christian, M. Rad, Psychosomatic medicine (GEOTAR Meditsina, Moscow, 1999)

16. M. Rastam, Ch. Gillberg, European Child and Adolescent Psychiatry 1 (1992) https://doi.org/10.1007/BF02084434

17. P.V. Krasnova, Difficult patient 8-9(14), 40-42 (2016) https://t-pacient.ru/wpcontent/uploads/2017/01/9.pdf

18. H. Tran, P. Poinsot, S. Iceta, Food addiction as a proxy for anorexia nervosa severity: new data based on the yale food addiction scale $\mathbf{2 9 3}$ (2020) https://doi.org/10.1016/j.psychres.2020.113472

19. S. Miles, I. Gnatt, A. Phillipou, M. Nedeljkovic, Clinical Psychology Review 81 (2020) https://doi.org/10.1016/j.cpr.2020.101905 
20. V.M. Atamanov, T.P. Demicheva, E.S. Ivashova, Clinical Medicine 3(96), 262-266 (2018) DOI: 10.18821/0023-2149-2018-96-3-262-266

21. A.F. Muratore, E. Attia, Clinical Therapeutics 43(1), 85-94 (2021) https://doi.org/10.1016/j.clinthera.2020.11.006 